\title{
Efeito do pH do solo em diferentes níveis de concentração de inóculo no controle de Plasmodiophora brassicae
}

\author{
Lucimeris Ruaro ${ }^{1}$, Vismar da Costa Lima Neto ${ }^{1}$, Antonio Carlos Vargas Motta ${ }^{2}$
}

${ }^{1}$ Departamento de Fitotecnia e Fitossanitarismo, ${ }^{2}$ Departamento de Solos e Engenharia Agrícola, Universidade Federal do Paraná, CEP 80035050, Curitiba PR.

Autor para correspondência: Lucimeris Ruaro (lucimeris@ufpr.br)

Data de chegada: 20/08/2008. Aceito para publicação em: 30/10/2009.

\section{RESUMO}

Ruaro, L.; Lima Neto, V. da C.; Motta, A.C.V. Efeito pH do solo e da concentração de inóculo no controle de Plasmodiophora brassicae. Summa Phytopathologica, v.36, n.1, p.16-20, 2010.

A hérnia das crucíferas causada por Plasmodiophora brassicae é uma das mais importantes doenças no cultivo de espécies de Brassicas no Brasil. Nos Municípios da Região Metropolitana de Curitiba, PR a maioria dos solos está contaminada pelo patógeno Plasmodiophora brassicae agente causal da hérnia das crucíferas, inviabilizando o cultivo de espécies de Brassicas em diversas propriedades. A calagem utilizada para elevar o $\mathrm{pH}$ do solo é uma das medidas de controle mais indicadas. Diante disso, o objetivo deste trabalho foi avaliar o efeito do $\mathrm{pH}$ do solo em diferentes concentrações de inóculo, no controle de $P$. brassicae. Foram utilizados quatro níveis de $\mathrm{pH}$ do solo: 4,$3 ; 5,5 ; 6,2$ e 7,3 e três concentrações de inóculo: $1.2 \times 10^{7} ; 2.5 \times 10^{7}$; e $5 \times 10^{7}$ esporos $\mathrm{mL}^{-1}$ e testemunha não inoculada. A suspensão de esporos foi obtida a partir de raízes de couve-chinesa com sintomas de hérnias e adicionado no colo das plantas, por ocasião do transplante das mudas de couve-chinesa (Brassica rapa var. pekinensis), para os vasos. Aos 45 dias após a inoculação, foram realizadas as avaliações. $\mathrm{O}$ efeito do $\mathrm{pH}$ sobre a severidade da doença foi mais expressivo em concentrações médias de inóculo $\left(1.2 \times 10^{7}\right.$ a $2.5 \times 10^{7}$ esporos $\left.^{-\mathrm{mL}^{-1}}\right)$. Em concentrações elevadas de inóculo, a severidade da doença foi reduzida em $\mathrm{pH}$ do solo de 6.2 e 7.3. O melhor desenvolvimento das plantas, quantificado pelo acúmulo de massa seca foliar foi obtido nos tratamentos onde o solo apresentou pH 6,2 e 7,3 e com a menor concentração de inóculo.

Pala vras-chave adicionais: hérnia, calagem, supressividade, Brassica rapa var. pekinensis.

\section{ABSTRACT}

Ruaro, L.; Lima Neto, V. da C.; Motta, A.C.V. Soil pH and inoculum concentration on the control of Plasmodiophora brassicae effect. Sum ma Phytopathologica, v.36, n.1, p.16-20, 2010.

Clubroot of the crucifers caused by Plasmodiophora brassicae is one of the most important diseases in the cultivation of Brassica species. In the Metropolitan Region of Curitiba, PR most of the soil is contaminated by the pathogen Plasmodiophora brassicae infesting agent of the clubroot of the crucifers making the cultivation of different species not feasible in many properties. Liming to increase soil $\mathrm{pH}$ is one of the most recommended control measures. Whereupon the objective of this work was to evaluate the effect of soil $\mathrm{pH}$ in different inoculums concentrations in the control of P. brassicae. Four levels of soil $\mathrm{pH}$ were used: 4,$3 ; 5,5 ; 6,2$ and 7,3 and three inoculums concentrations: $1.2 \times 10^{7}, 2.5 \times 10^{7} 5 \times 10^{7}$ spores $\mathrm{mL}^{-1}$ and non-inoculated control. The spores suspension was obtained from Chinese cabbage roots showing galls and it was added to the plant collars when the Chinese cabbage (Brassica rapa var. pekinensis) seedlings were transplanted to pots. At 45 days after inoculation the evaluations were performed. The effect of $\mathrm{pH}$ on the disease severity was more expressive with the average inoculums $\left(1.2 \times 10^{7}\right.$ to $2.5 \mathrm{x}$ $10^{7}$ spores $\mathrm{mL}^{-1}$ ) With the higher inoculums concentrations the disease severity was reduced in soil $\mathrm{pH} 6,2$ and 7,3. The best development of the plants assessed by the accumulation of foliar dry phytomass was obtained where the soil presented $\mathrm{pH}$ between 6,2 and 7,3 and with the lowest inoculum concentration.

Keywords: galls, liming, supressiviness, Brassica rapa var pekinensis.

Dentre as olerícolas mais cultivadas, as espécies pertencentes às famílias Brassicaceae representadas pelo repolho, couve-flor, brócolos, mostard a e couve-chinesa se destacam pela sua expressão econômica, principalmente nas regiões Sudeste e Sul do Brasil. A Região Metropolitana de Curitiba-PR (RMC) é responsável por cerca de $70 \%$ da produção de olerícolas do estado do Paraná, abastecendo o merc ado de Curitiba e outros centros consumidores do País (18).

Das doenças que incidem nessas culturas, a hérnia das crucíferas causada por Plasmodiophora brassicae Woronin é uma das mais importantes e está presente nas regiões Sul e Sudeste, especialmente em locais com clima úmido e temperaturas mais baixas, como Minas Gerais, São Paulo, Paraná, Santa Catarina e Rio Grande do Sul, com tendência a ser mais grave emáreas onde estas espécies são cultivadas intensivamente (26). A maioria dos solos nos municípios da RMC está contaminada pelo patógeno, chegando a inviabilizar o cultivo de brás sicas em muitas propriedades (13).

No processo de colonização, o patógeno induz o desenvolvimento de hérnias no sistema radicular, a planta passa a exibir murcha nas horas mais quentes do dia, subdesenvolvimento e o apodrecimento antecipado do sistemaradicular, culminando com a liberação de esporos 
de resistência. Nesta condição, o patógeno pode permanec er no solo por longos períodos. Es tudos de campo indicam que os esporos têm uma meia-vida de pelo menos 3,6 anos e alguns deles podem existir por 18 anos, na ausência de hospedeiros (23).

A doença é favorecida quando a temperatura os cila entre 18 e 25 ${ }^{\circ} \mathrm{C}$, o solo é arenoso, e o $\mathrm{pH}$ é ácido. Esta última condição é preponderante no desencadeamento e desenvolvimento da infecção (23). Segundo Webster \& Dixon (25) a doença é mais severa em pH menores que 5,7; entre 5,7 e 6,2 a severidade da doença decresce e acima de pH 7,8 o patógeno é complemente inibido. Niwa et al. (17) afirmam que a germinação dos esporos e a subseqüente colonização dos pelos da raiz são inibidas pela presença de cálcio e valores de $\mathrm{pH}$ alc alino.

Geralmente a aplicação de calcário para elevar o pH do solo apresenta bons resultados, mas não é raro a redução da doença através desta medida acabar em resultados insatisfatórios (9). Diversos fatores podem modificar o resultado da calagem no controle da hérnia das crucíferas. Larson \& Walker (12) correlacionaram um controle insuficiente a diferentes níveis de incorporação do calcário ao solo. Chupp \& Sherf (2) destacam a importância de uma espera de seis a oito semanas, após a aplicação do calcário para obter-se um bom controle da doença. Níveis elevados de inóculo de $P$. brassicae permitiram infecções em plantas cultivadas em solos com $\mathrm{pH}$ de até 8,0 (3). E solos diferentes podem reagir de formas também diferentes à ap licação de calcário para o controle da hérnia das crucíferas (15).

Myers et al. (15) relatam que o pH do solo isoladamente não é uma indicação confiável de potencial para controle da hérnia das crucíferas em todos os solos. Ainda segundo os mesmos autores, aparentemente, o pH e a concentração de inóculo poderiam funcionar de forma interativa, afetando processos como a invasão, a colonização e os sintomas de formação de hérnias. Webster \& Dixon (25) verificaram que o efeito do $\mathrm{pH}$ no controle da doença foi mais efetivo em baixas concentrações de inóculo do patógeno. Na RMC tem sido observada ocorrência severa da doença mesmo em propriedades onde a calagem é realizada e os valores médios do $\mathrm{pH} \mathrm{CaCl}_{2}$ das amostras de solo, coletadas nas covas das plantas, estão entre 6,8 e 7,2. Ruaro et al. (18) verificaram que a calagem não foi suficiente para reduzir a incidência da hérnia das crucíferas nos solos da região metropolitana de Curitiba. Pesquisas referentes aos efeitos do $\mathrm{pH}$ em solos com diferentes concentrações de inóculono controle de $P$. brassicae são escassos e conta-se com os trabalhos de Webster \& Dixon (25). Contudo, Dixon (8) destaca que fatores como pH do solo, concentração de inóculo e planta hos pedeira podem influenciar de modo diferente algumas raças fisiológicas de $P$. brassicae. Pouco se sabe sobre as populações brasileiras deste patógeno, mas há indícios sobre diferenças exis tentes entre populações heterogêneas conforme estudos realizados por Cruz et al. (5). Assim, é fundamental o entendimento dos efeitos desses fatores em condições brasileiras.

O presente trabalho teve como objetivo avaliar o efeito do $\mathrm{pH}$ do solo em diferentes concentrações de inóculo de $P$. brassicae na severidade da doença, na produção da parte aérea e no desenvolvimento do sistema radicular de plantas de couve chinesa.

\section{MATERIALE MÉTODOS}

O experimento foi conduzido no Setor de Ciências Agrárias da UFPR, Curitiba, PR, em condições parcialmente controladas de casa de vegetação $\left( \pm 25^{\circ} \mathrm{C}\right)$, durante os meses de agosto à outubro. Os valores de $\mathrm{pH}$ utilizados no experimento foram: 4,3; 5,5; 6,2 e 7,3. Para a determinação da quantidade de calcário necessária para se atingir esses valores de $\mathrm{pH}$, realizou-se a incubação do solo com doses crescentes de calcário, correspondendo a $0 ; 2,5 ; 5,0 ; 10,0 ; 15,0 ; 20,0$; 30,0 e 35,0 t.ha ${ }^{-1}$, a unidade experimental era constituída de um vaso de plástico contendo $1 \mathrm{~kg}$ de solo, com cinco repetições. Foi utilizado calcário calcítico com Poder Relativo de Neutralização de 104,5\%. Após a aplicação do calcário, o pH do solo foi monitorado, até a estabilização dos valores, que ocorreu aos 30 dias. Durante esse período, a umidade do solo foi mantida na capacidade de campo, pela adição de água a cada 48 hora. Após o período de incubação, amostras de $10 \mathrm{~g} \mathrm{de}$ solo foram retiradas dos vasos, para compor uma amostra composta por tratamento, e foram submetidas à análise para determinação dos valores de $\mathrm{pH}$. A partir dos valores de $\mathrm{pH}$ obtidos para as doses de calcário acima citadas, foi elaborada a curva de calibração, que indicou a necessidade de calagem de $0 ; 6,0 ; 12,0$ e $21,0 \mathrm{~g}$ de calcário. $1,5 \mathrm{~kg}^{-1} \mathrm{de}$ solo, respectivamente para se atingir o $\mathrm{pH}$ de 4,$3 ; 5,5 ; 6,2$ e 7,3. As doses de calcário foram aplicadas ao solo 30 dias antes do transplante das mudas. Durante este período os vasos foram irrigados com água destilada e deionizada até a saturação dos mesmos para otimizar a reação do calcário no solo. As características do solo anteriore posterior à ap licação de calcário, estão apresentadas na Tabela 1 .

A adubação nitrogenada, fosfatada e potássica seguiram as recomendações apresentadas pela Comis são de Química e Fertilidade do Solo (4). As quantidades utilizadas foram: $150 \mathrm{mg}$ de N, $375 \mathrm{mg}$ de $\mathrm{P}_{2} \mathrm{O}_{5}$ e $225 \mathrm{mg}$ de $\mathrm{K}_{2} \mathrm{O}$, as quais foram aplicadas e homogeneizadas em cada vaso. As fontes utilizadas foram respectivamente: nitrato de cálcio, superfosfato simples e cloreto de potássio. Em cobertura, foram aplicadas $45 \mathrm{mg}$ de $\mathrm{N} \cdot 1,5 \mathrm{~kg}^{-1}$ de solo na forma de nitrato de cálcio, aos 15 e 30 dias após o transplante.

Foram utilizadas mudas de couve-chinesa cultivar suscetível (Brassica rapa var. pekinensis) Pak choi, produzidas em bandejas contendo substrato inerte à base de vermiculita. Aos 10 dias após a

Tabela 1. Características do solo utilizado na avaliação do efeito do pH e de diferentes concentrações de inóculo no controle da hérnia das crucíferas (Plasmodiophora brassicae).

\begin{tabular}{cc|c|c|c|ccc|c|cc|c|cc}
\hline $\begin{array}{c}\mathrm{pH} \\
\mathrm{CaCl}_{2}\end{array}$ & $\mathrm{Al}^{-3}$ & $\mathrm{H}+\mathrm{Al}$ & $\mathrm{Ca}^{-2}+\mathrm{Mg}^{+2}$ & $\mathrm{Ca}^{+2}$ & $\mathrm{~K}^{+}$ & $\mathrm{T}$ & $\begin{array}{c}\mathrm{P} \\
\mathrm{mg} \cdot \mathrm{dm}^{-3}\end{array}$ & $\begin{array}{c}\mathrm{M} \cdot \mathrm{O} \\
\mathrm{g} \cdot \mathrm{dm}^{-3}\end{array}$ & $\begin{array}{c}\mathrm{pH} \\
\mathrm{SM} \mathbf{I}_{\mathrm{e}} \cdot \mathrm{dm}^{-3}\end{array}$ & $\begin{array}{c}\mathrm{V} \\
\%\end{array}$ & $\begin{array}{c}\text { Areia } \\
\text { total } \\
\%\end{array}$ & $\begin{array}{c}\text { Silte } \\
\%\end{array}$ & $\begin{array}{c}\text { Argila } \\
\%\end{array}$ \\
\hline 4,3 & 3,1 & 10,5 & 1,0 & 0,7 & 0,20 & 11,7 & 0,6 & 27,5 & 5,0 & 10 & 30 & 22 & $\mathbf{4 8}$ \\
5,5 & 0,0 & 4,3 & 9,1 & 5,2 & 0,21 & 14,1 & 0,6 & 32,2 & 6,1 & 68 & 30 & 22 & 48 \\
6,2 & 0,0 & 3,2 & 11,2 & 6,0 & 0,20 & 14,6 & 0,6 & 29,6 & 6,6 & 78 & 30 & 22 & 48 \\
7,3 & 0,0 & 2,0 & 15,5 & 8,6 & 0,15 & 17,6 & 0,4 & 33,7 & 7,2 & 88 & 30 & 22 & 48 \\
\hline
\end{tabular}


semeadura, as mudas foram transplantadas (uma planta/vaso) para vasos de alumínio com capacidade de $1,5 \mathrm{~kg}$.

O inóculo de $P$. brassicae foi obtido a partir de raízes de couve chinesa com sintomas de hérnias, coletadas em plantio comercial da cultura com 50 dias de plantio, localizado no município de Colombo, PR. A coleta foi realizada após inspeção visual, selecionando-se plantas que apresentavam sintoma reflexo de murcha da parte aérea. Entre essas, escolheu-se as que apresentavam hérnias bem desenvolvidas, descartando-se aquelas em início de decomposição. Coletou-se $1 \mathrm{~kg}$ de raízes, que foram transportadas para o laboratório em saco de polietileno à temperatura ambiente. No mesmo dia em que foram coletadas, as raízes foram lavadas emágua corrente e em água destilada e esterilizada, sendo posteriormente acondicionadas em sacos de polietileno e mantidas à temperatura de $-20^{\circ} \mathrm{C}$, durante 45 dias. Segundo Dylewski (6) nessa temperatura os esporos de repouso do patógeno permanecem viáveis durante anos no tecido de raízes infectadas.

A extração dos esporos de repouso foi baseada na metodologia de Naiki \& Dixon, (16). Asuspensão de esporos de repouso de P. brassicae foi obtida pela homogeneização, em liquidific ador, de $134 \mathrm{~g}$ de raízes com hérnias acrescida de $100 \mathrm{~mL}$ de água destilada e esterilizada. A mistura foi filtrada através de quatro camadas finas de "musseline" e em seguida centrifugada (sigma $3 \mathrm{~K} 30$ ) por 10 minutos a 45.000xg. O filtrado obtido foi ressuspenso em $50 \mathrm{~mL}$ de água destilada e esterilizada e destilada, sendo os processos repetidos por duas vezes consecutivas, e o filtrado final diluí do em $5 \mathrm{~mL}$ de água destilada e esterilizada. Com o auxílio de hemacitômetro foram calibradas suspensões com as seguintes quantidades de inóculo: $1.2 \times 10^{7}, 2.5 \times 10^{7}$ e $5 \times 10^{7}$ esporos $\mathrm{mL}^{-1}$. Para o transplante das mudas, a umidade do solo foi medida gravimétricamente (p/p) (22). O solo foi irrigado em aproximadamente $3 / 4$ da capacidade de campo que correspondeu a $225 \mathrm{~mL}$ de água esterilizada e deionizada em c ada vaso. Na sequiência, foi realizado o transplante das mudas e a inoculação do patógeno, adicionando-se $25 \mathrm{~mL}$ de cada suspensão no colo das plantas, na forma de rega. Duas horas após o transplante e a inoculação, para elevar a umidade à capacidade de campo completou-se a rega com 75 $\mathrm{mL}$ de água em cada vaso (10).

Aos 45 dias após a inoculação, as raízes foram lavadas e avaliadas, determinando-se o índice de severidade da doença em porcentagem (7). Para tanto foi utilizad a uma escala visual de notas variando de 0 a III $(0=0 \%, I=1-29 \%, I I=30-59 \%, I I I=60-100 \%)$, conforme a porcentagem da área radicular afetada. O índice de severidade da doença (ID) foi calculado de acordo com a fórmula: $\mathrm{ID}=\Sigma(\mathrm{n} \times \mathrm{c}) 100 /$ $\mathrm{N} x$ 3. Onde: ID: Índice de doença; $\mathrm{n}=$ número de raízes em cada categoria; $\mathrm{c}=$ categoria e $\mathrm{N}=$ número total de raízes examinadas. A parte aérea e radicular das plantas foi destacada, lavadas e submetidas à sec agem em es tufa de circulação forçada a $70^{\circ} \mathrm{C}$ por 72 horas. Após a secagem, determinou-se o acúmulo de massa seca foliar (MSF) e de mass a seca radicular (MSR) das plantas de couve chinesa.

$\mathrm{O}$ experimento foi conduzido em blocos ao acaso, e tratamentos em ensaio fatorial. Cada tratamento contou com quatro repetições, cada repetição foi composta de um vaso com uma planta. Os resultados foram submetidos à análise de variância e, quando obtidos valores significativos, realizada a análise de regressão. O logaritmo das variáveis massa seca foliar (MSF) e de massa seca radicular (MSR) foram sugeridos como transformação para aproximação da distribuição normal dos erros. Para as análises, utilizou-se o programa R, cujo manual é descrito por Ihaka e Gentleman (11) e as referências básicas estão no "CRAN" (Comprehensive R archive network). Outro software utilizado como apoio foi o STATGRAPHCS PLUS para Windows.

\section{RESULTADOS E DISCUSSÃO}

A interação significativa entre os níveis de $\mathrm{pH}$ do solo e a concentração de inóculo, influenciou os seguintes atributos: severidade da doença, massa seca foliar (MSF)e de mas sa seca radicular (MSR) das plantas de couve-chinesa. Verificou-se que aumentando a concentração de inóculo para níveis mais elevados como $5 \times 10^{7}$ esporos $\mathrm{mL}^{-1}$, a severidade da doença aumentou mesmo em níveis mais altos de $\mathrm{pH}$ do solo como 7,3 (Figura 1A). O melhor desenvolvimento das plantas, medido por meio da MSF, foi obtido com pH entre 6,2 e 7,3 no tratamento sem inoculação e no tratamento com a menor concentração de inóculo aplicada $\left(1.2 \times 10^{7}\right)$ (Figura 1B).

Inserir Figura 1

$\mathrm{O}$ peso da raiz sofreu aumento significativo quando comparado os $\mathrm{pH} 4,3,5,5$ e 6,2 com o $\mathrm{pH}$ 7,3 principalmente no tratamento com maior concentração de inóculo do patógeno (Figura 1C). Segundo Miller et al. (14) P. brassicae interfere no metabolismo hormonal da planta, ocasionando hiperplasia e hipertrofia dos tecidos das raízes e como conseqüência tem-se um aumento no volume e no peso do tecido atacado. Como pode ser observado na Figura 2, a severidade da doença foi maior nos tratamentos com $\mathrm{pH}$ 4,3 quando comparada em $\mathrm{pH}$ 7,3, confirmando que o patógeno é favorecido pela acidez.

Inserir Figura 2

$\mathrm{O}$ efeito do $\mathrm{pH}$ sobre a severidade da doença foi mais expres sivo em concentrações médias $\left(1.2 \times 10^{7}\right.$ e $2.5 \times 10^{7}$ esporos $\left.\mathrm{mL}^{-1}\right)$ que em concentrações elevadas de inóculo, corroborando comos dados citados por Webster \& Dixon (25), os quais utilizaram como menor concentração de inóculo $5 \times 10^{5}$ esporos $\mathrm{mL}^{-1}$ e como maior conc entração $5 \times 10^{7}$ esporos $\mathrm{mL}^{-1}$ concluíram que a manipulação de valores de $\mathrm{pH}$ teve efeitos maiores no desenvolvimento da doença em pressões de inóculo mais baixas. Os autores argumentam que o $\mathrm{pH}$ alcalino reduz a infecção de pêlos radiculares e a taxa de maturação dos esporângios no interior destes pêlos. No presente trabalho constatou-se também, que a manipulação dos valores de $\mathrm{pH}$ teve efeito representativo na severidade da doença em menores concentrações de inóculo. Portanto, para solos altamente infestados o uso da calagem poderá ser insuficiente para controlar a doenca. Contrário aos resultados observados neste trabalho, Wang \& Hsieh (24) utilizando concentrações de $10^{5}, 10^{6}, 10^{7}$ e $10^{8}$ esporos/g de solo verificaram que a severidade da doença causada por $P$. brassicae, independente da concentração de inóculo, foi maior até pH 5,7. Já entre $\mathrm{pH} 5,8$ e 6,2 a severidade da doença decresceu acentuadamente sendo o patógeno completamente inibido em $\mathrm{pH}$ acima de 7,8 e Chattopadhyay (1) ao trabalhar com $P$. brassicae em colza verificou que a correção do solo com calcário para $\mathrm{pH}$ 7,2 e 7,3 reduziu a incidência da doença e a severidade de $P$. brassicae, independente da quantidade de inóculo. Porém, anteriormente a estes autores, Colhoun (3) constatou que em solos com alta concentração de inóculo e com pH 7,8 ocorre ataque intenso do patógeno. De modo semelhante, Samuel \& Garret (19) observaram infecções nos pêlos das raízes utilizando uma mis tura de areia e solo com $\mathrm{pH} 7,7$, apenas com elevada concentração de esporos de $P$. brassicae.

$\mathrm{O}$ controle da hérnia das crucíferas por meio do aumento do $\mathrm{pH}$ do solo acima de 7,2 tem gerado controvérsias há vários anos. Uma corrente de pesquisadores como Smiley \& Cook (20) e Hamilton \& Crête (10) enfatizam que a controvérsia é devida às metodologias utilizadas na determinação do $\mathrm{pH}$. Para uma mesma amostra de solo o $\mathrm{pH}$ em água é maior do que o $\mathrm{pH}$ em $\mathrm{CaCl}_{2}$, mas esta diferença não tem um valor fixo. Em solos muito ácidos, a diferença pode chegar a 1,0 unidade. Entretanto, em solos próximos à neutralidade, os dois 

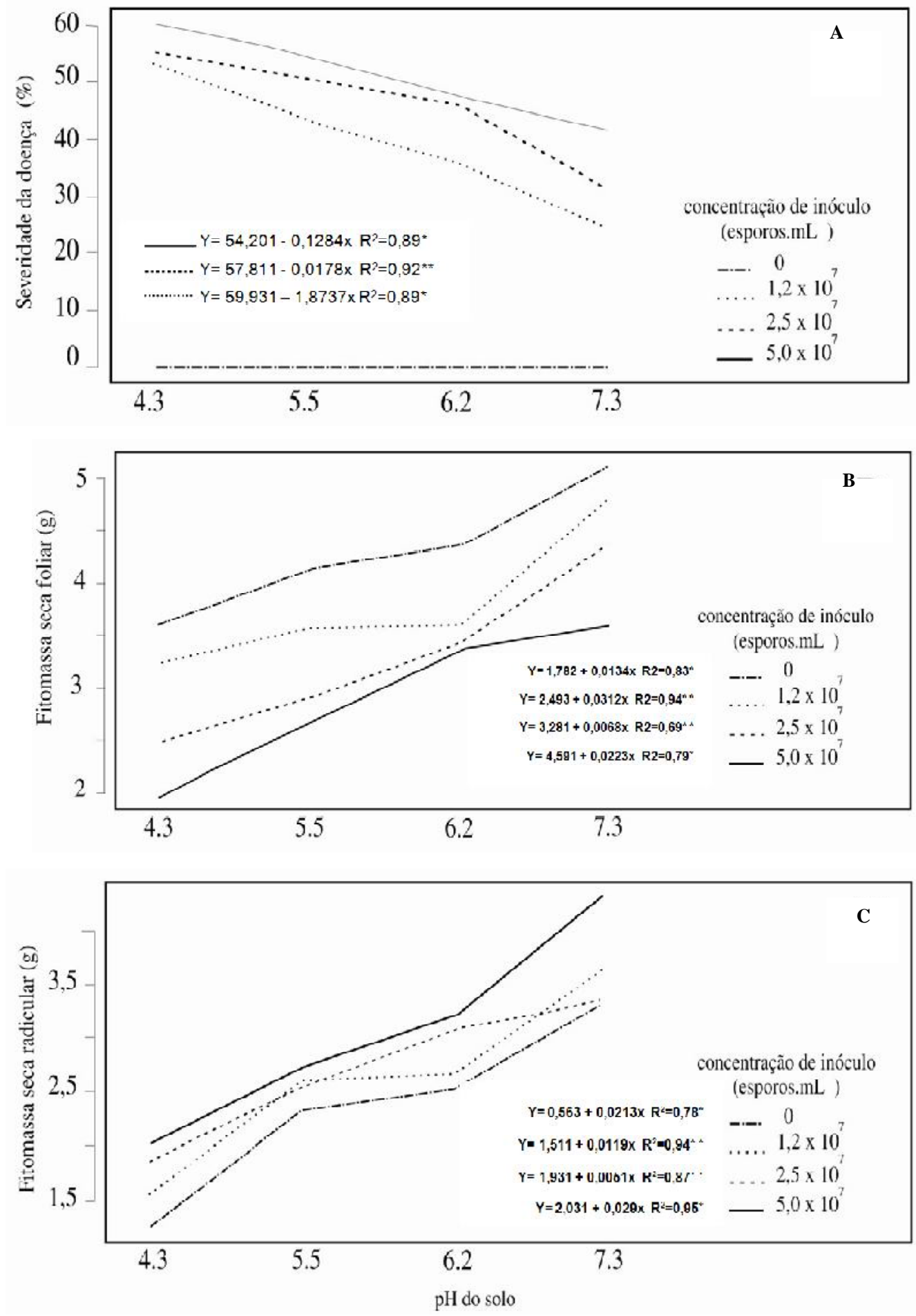

Figura 1. Interação entre concentração de inóculo de Plasmodiophora brassicae e níveis de pH do solo, na severidade da doença (A); na produção de fitomassa seca foliar (B) e na produção de fitomassa seca radicular (C) de plantas de couve chinesa.

valores podem seriguais (21). Esta variação apresentad a pelos valores de $\mathrm{pH}$ do solo, dependendo da metodologia utilizada, dificulta a comparação entre os dois índices $(10,20)$. Em experimentos com $P$. brassicae, Smiley \& Cook (20) encontraram em amostra de solo valores de $\mathrm{pH}$ em água de 7,2 correspondente a um $\mathrm{pH} 6,7 \mathrm{em} \mathrm{CaCl}_{2}$, sendo essa diferença de 0,5 unidades de $\mathrm{pH}$ representativa para o controle do patógeno por meio da calagem.
Nos tratamentos com maior concentração de inóculo, onde a severidade da doença foi maior, não se observou aumento proporcional do peso das plantas com a elevação do pH do solo (Figura 1A e 1B). Verificou-se também, que para elevar o $\mathrm{pH}$ do solo utilizado de 5,5 para 7,3 foi necessário $25 \mathrm{tha}^{-1}$ de calcário, que representa uma quantidade de corretivo considerável. Conforme Raij(21) a necessidade de calcário para elevar o pH do solo está relacionada à sua capacidade 


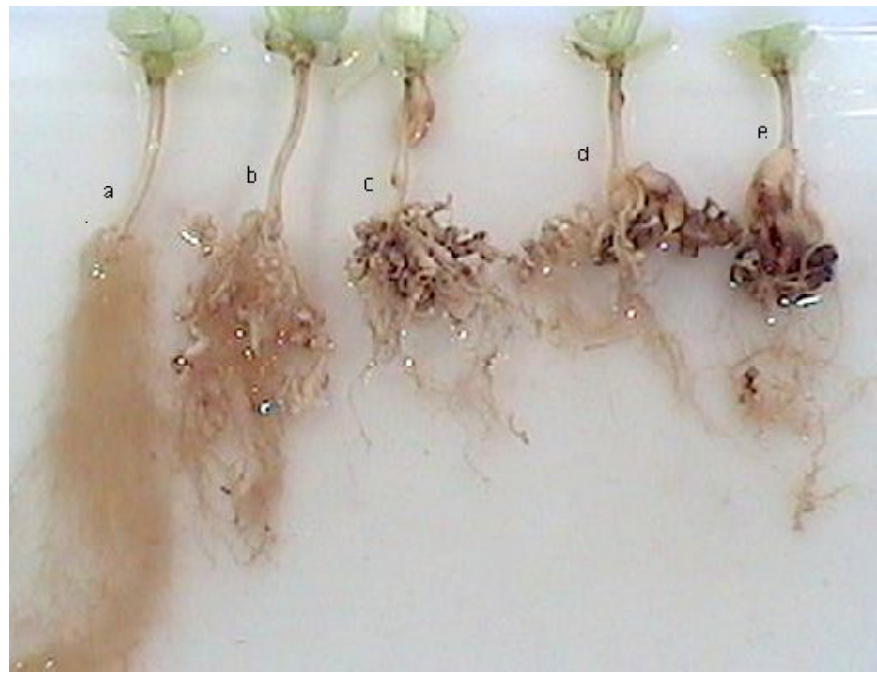

Figura 2. Severidade da doença em raízes de couve chinesa desenvolvidas em solos com diferentes concentrações de inóculo de Plasmodiophora brassicae versus níveis de $\mathrm{pH}$ do solo. a: testemunha; b: $1,2 \times 10^{7}$ esporos $\mathrm{mL}^{-1} \mathrm{e} \mathrm{pH} 7,3 ; \mathbf{c}: 1,2 \times 10^{7}$ esporos $\mathrm{mL}^{-1}$ e $\mathrm{pH} 4,3 ; \mathbf{d}: 2,5 \times 10^{7}$ esporos $\mathrm{mL}^{-1}$ e $\mathrm{pH} 7,3$; e: $2,5 \times 10^{7}$ esporos $\mathrm{mL}^{-1}$ e $\mathrm{pH} 4,3$.

tampão, ou seja, quão fortemente ele resiste às mudanças de $\mathrm{pH}$. Essa capacidade tampão aumenta com as quantidades de matéria orgânica e de argila presentes no solo. Como se observa na Tabela 1 o solo utilizado apresenta níveis altos de matéria orgânica e de argila. Nestas condições, quantidades elevadas de calcário são necessárias para elevar o pH do solo. A relação custo/benefício no controle da doença deve ser mensurada quando envolver solos com altas concentrações de inóculo, e que ao mesmo tempo exijam grandes quantidades de calcário para a elevação dos seus níveis de $\mathrm{pH}$., visando a supressividade do solo à $P$. brassicae.

Os resultados obtidos no presente trabalho indicaram que a elevação do $\mathrm{pH}$ do solo visando a supressividade do solo à $P$. brassicae apresenta resultados positivos em solos com concentrações baixas ou médias de inóculo do patógeno. Em solos com concentrações elevadas de inóculo a severidade da doença não é reduzida ao se modificar o $\mathrm{pH}$ do solo para níveis mais elevados como 6,2 e 7,3.

\section{REFERÊNCIAS BIBLIOGRÁFICAS}

1. Chattopadhyay, A. K. Soil amendment with lime and organic matter on the control of clubroot disease of rapeseed mustard. Indi an Phytopathology, New Delhi, v.49, n.3, p.283$285,1996$.

2. Chupp, C.; Sherf, A.F. Vegetable diseases and their control. New York: Ronald Press., 1960. 693 p.

3. Colhoun, J. Spore load, light intensity and plant nutrition as factors influencing the incidence of clubroot of Brassicae. Transactions of the British. Mycological Society, Kew, v.44, p.593-600, 1961.

4. Comissão de Química e Fertilidade do Solo. Recomendações de adubação e de calagem para os estados do Rio Grande do Sul e Santa Catarina. 3.ed. Passo Fundo: Sociedade Brasileira de Ciência do Solo, 1995. 100 p.

5. Cruz, J.C.S.; Souza, N.L.; Nakatani, A.K.; Rosa, D.D.; Basseto, M.A.; Padovani, C.R.; Furtado, E.L. Caracterização patogênica e molecular de Plasmodiophora brassicae. Tropical Plant Pathology, Brasília, v.33, n.6, p.415-424, 2008.

6. Dylewski, D.P. Phylum Plasmodiophoro-mycota. p. 399-416. In: Margulis, L., Corliss, J.O., Melkonian, M., Chapman, D.J.
(Ed.). Handbook of protoctista. Boston:Jones and Bartlett, 1990.

7. Dixon, G.R.; Robinson, D.L. The susceptibility of Brassica oleracea cultivars to Plasmodiophora brassicae (clubroot). Plant Pathology, Oxford, v.35, p.101-107, 1996

8. Dixon, G.R. Plamodiophora brassicae in its Environment. Journal of Plant Growth Regulation. DOI: 10.1007/s00344-009-90983. Disponível em: http://www.springerlink.com/content/ wk7415m6u1018082/. Acesso em: 13 jun. 2009.

9. Dobson, R.L.; Gabrielson, R.L.; Baker A.S.; Bennett L. Effects of lime particle size and distribution and fertilizer formulation on clubroot disease caused by Plasmodiophora brassicae. Plant Disease, St. Paul, v.67, n.1, p. 50-52, 1983.

10. Hamilton, H.A.; Crete, R. Influence of soil misture, soil $\mathrm{pH}$ and liming sources on the incidence of clubroot, the germination and growth conditions. Canadi an Journal of Plant Sci ence, Ottawa, v.58, p. 45-53, 1978.

11. Thaka, R.; Gentleman, R. A Language for data analysis and grafhics. Journal of Computational and Graphical Statistics, v.5, p. $299-314,1996$.

12. Larson, R.H.; Walker, J.C. Soil treatment in relation to clubroot of cabbage. Journal of Agricultural Research, Punjab, v.48, p.749-759, 1934

13. May, L.L. Avaliação de diferentes formas de controle de Plasmodiophora brassicae em couve-chinesa em condições de casa de vegetação. Revista do Setor de Ciências Agrárias. Curitiba, n. 1-2, p. $9-14,1997$.

14. Miller, S.A.; Rowe, R.C.; Riedel, R.M. Clubroot of crucifers. The Ohio State University Extension. Plant Pathology. Disponível em: http://www.ohioline.osu.edu/hyg-fact . Acesso em: 8 Fev. 2002.

15. Myers, D.F.; Campbell, R.N.; Greathead, A.S. Clubroot of crucifers in California: Soils respond differently to lime from clubroot control Phytopathology, St. Paul, v.71, p.1005-1006, 1981. (Abstract).

16. Naiki, T.; Dixon, G.R. The effects of chemicals on developmental stages of Plasmodiophora brassicae. Plant Pathology, Bangor, v.36, p.316-327, 1987.

17. Niwa, R.; Nomura, Y.; Osaki, M.; Ezawa, T. Suppression of clubroot disease under neutral $\mathrm{pH}$ caused by inhibition of spore germination of Plasmodiophora brassicae in the rhizosphere. Plant Pathol, Bangor, v.57, p.445-452, 2008.

18. Ruaro, L.R.; Lima Neto, V.da C.; Nowacki, J.C. Controle da hérnia das crucíferas na Região Metropolitana de Curitiba. Relatório Técnico. Curitiba: UFPR/SEAB-PR. 2003. 87p.

19. Samuel, G.; Garret, S.D. The infected root-hair count for estimating the activity of Plasmodiophora brassicae Woron. in the soil. Annals of Applied Biology, Wellesbourne, v.32, p.96-101, 1945.

20. Smiley, R.W.; Cook, R.J. Use and abuse of the soil pH measurement. Phytopathology, St. Paul, v.62, p.193-194, 1972.

21. Raij, B.van Fertilidade do solo e adubação. São Paulo: Agronômica Ceres, 1991. 343 p.

22. Vieira, F.C.S. Microrganismos e atividade microbiana em latossolo submetido a diferentes condições de conservação. Jaboticabal, 1995. 50p. Monografia (Graduação) - Faculdade de Ciências Agrárias e Veterinárias de Jaboticabal, Universidade Estadual Paulista "Julio de Mesquita Filho".

23. Wallenhamar, A.C. Monitoring and control of Plasmodiophora brassicae in spring oilseed brassica crops. Acta Universitatis Agriculturae Sueciae, Agraria 183. Swedish University of Agricultural Sciences, Uppsala, p. 53, 1999.

24. Wang, J.F.; Hsieh, W.H. Studies on the supressive factors and characteristics of supressive soils of clubroot in crucifers. Plant Protection Bulletin, Cidade, v.28, p.363-370, 1986.

25. Webster, M.A.; Dixon, G.R. Calcium, pH and inoculum concentration influencing colonization by Plasmodiophora brassicae. Mycological Research, Amsterdam, v.95, n.1, p.80-85. 1991.

26. Zambolim, L., Casa, R.T.; Reis, E.M. Sistema plantio direto e doenças de plantas. Fitopatologia Brasileira, Brasília, v. 25, p. $585-595,2000$. 